\title{
MAPPING AND CHANGE DETECTION OF MANGROVES AROUND MUMBAI USING REMOTE SENSING AND GEOGRAPHIC INFORMATION SYSTEMS (GIS)
}

\author{
A. Abhyankar", T. Sahoo, B. Seth, P. Mohapatra, S. Palai, P. Bhargava, S. Chaurasiya and S. Isasare \\ National Institute of Construction Management and Research, Pune-45, Maharashtra, India.
}

Date received: 13/12/2020 Date accepted: 05/04/2021
*Corresponding author's email: aabhyankar@ nicmar.ac.in
DOI: $10.33736 /$ jcest.3339.2021

Abstract-The study focuses on the mangroves in two districts namely, Mumbai and Mumbai Suburban. Mumbai, a coastal megacity, is a financial capital of the country with high population density. Mumbai is facing depletion of coastal resources due to land scarcity and large developmental projects. Thus, it is important to monitor these resources accurately and protect the stakeholders' interest. Cloud-free satellite images of IRS P6 LISS III of 2004 and 2013 were procured from National Remote Sensing Centre (NRSC), Hyderabad. Two bands of visible and one band of NIR were utilized for landcover classification. Supervised Classification with Maximum Likelihood Estimator was used for the classification. The images were classified into various landcovers classes namely, Dense Mangroves, Sparse Mangroves and Others. Two software's namely, ERDAS Imagine and GRAM++ were used for landcover classification and change detection analysis. It was observed that the total mangrove area in Mumbai in 2004 and 2013 was 50.52 square kilometers and 48.7 square kilometers respectively. In the year 2004 and 2013, contribution of sparse mangroves in the study area was $72.31 \%$ and $87.06 \%$ respectively.

Copyright $\odot 2021$ UNIMAS Publisher. This is an open access article distributed under the Creative Commons Attribution-NonCommercial-ShareAlike 4.0 International License which permits unrestricted use, distribution, and reproduction in any medium, provided the original work is properly cited.

Keywords: Change Detection, Geographic Information Systems, Mangrove, Maximum Likelihood Estimator, Remote Sensing, Change Detection, Supervised Classification

\section{INTRODUCTION AND OBJECTIVES}

Mangroves are the trees and shrubs that are highly decisive coastal resources which grow in saline coastal habitats in the tropics and subtropics having stilt like roots and stems and forming dense thickets along tidal shores. These provides various necessary ecosystem services like maintaining the quality of coastal waters, bio resources, reducing intensity of storm and flood damage and it is also a breeding ground for fish species [1;2]. It sustains directly 70 human activities [3; 4]. They protect the shore line which is a buffer zone between land and sea. Also, mangrove forests play a pivotal role that includes screening the UV-B radiation and reducing the greenhouse gases $\left(\mathrm{CO}_{2}\right)$. It is a natural shield against cyclones and ecological disasters. It is a place of sustaining various marine species; removing harmful heavy metals and finally providing economic benefits. It is a source of timber, fuel fodder and income for fishermen [5].

Before the use of remote sensing as a tool of mangrove mapping, field survey was the available option. Such a survey-based technique has limitations which were overcome by remote sensing technology. The inherent advantages of remote sensing data include synoptic coverage, temporal revisit time, large spatial area coverage; data easily available and less cost, images give true picture and highly accurate, satellite images available with various resolutions, inaccessible area coverage possible and all time (day and night) and availability of satellite data during extreme weather. Remote sensing as a tool finds extensive applicability in coastal resources mapping and management especially mangroves mapping [6;7]. Medium and low resolution satellite images have been extensively used during last four decades for mangrove mapping and monitoring, namely Landsat [8; 9], SPOT [10], IRS [11; 12], ERS [13], Sentinel-1 and Sentinel-2 [14] etc.

In the initial years, a mangrove mapping using remotely sensed data was performed by visual interpretation techniques. The elements of photo interpretation were used for mangrove classification $[15 ; 16 ; 17]$. Further, past literatures had proven the relevance of remote sensing in mangrove mapping and change detection [18; 19]. Later years various digital image processing techniques had been employed by various researchers that include Normalized Difference Vegetation Index (NDVI) [20; 21], Maximum Likelihood Estimator (MLE) [22; 23] and Neural Network [24]. The results obtained from these techniques were found better than visual interpretation in 
terms of accuracy of classification. From the literature, it is clear that limited work is carried out on classification of dense and sparse mangroves using medium resolution satellite images and MLE. The specific objectives of the present study are to identify Mangroves in Mumbai using RS and GIS and conduct a change detection analysis using data of year 2004 and 2013.

\section{STUDY AREA}

Mumbai consists of two districts; Mumbai city or Island city and Mumbai Suburban district and is shown in Figure 1. Mumbai has a total area of about 603.4 square kilometers. The Island city spans 67.79 square kilometers and Mumbai suburban district coverage is 370 square kilometers which comes under the administration of Municipal Corporation of Greater Mumbai (MCGM) and the rest is of Mumbai Port Trust, Atomic Energy Commission, Defense and Borivali National Park.

Mumbai is bounded by the Arabian Sea on the west (see Figure 1). The population which is constantly growing due to the urbanization and currently stands at about 20.5 million people is creating a direct impact on the coastal resources due to the unavailability of adequate land area. Expansion of human settlements to cope with the ever growing population and industrial setups along the coastal region has been disturbing the mangrove ecosystems and further depleting them. The mangroves in Mumbai region have been affected due to land reclamation and issues like pollution. The present mangroves are under threat from the human settlement expansion and urban activities. Plenty of urban and infrastructure development has been happening on or around the mangroves. Industrial developments around the coastline make the mangroves vulnerable due to improper disposal of wastes. It is also destroyed by dumping of excavated earth for residential areas.

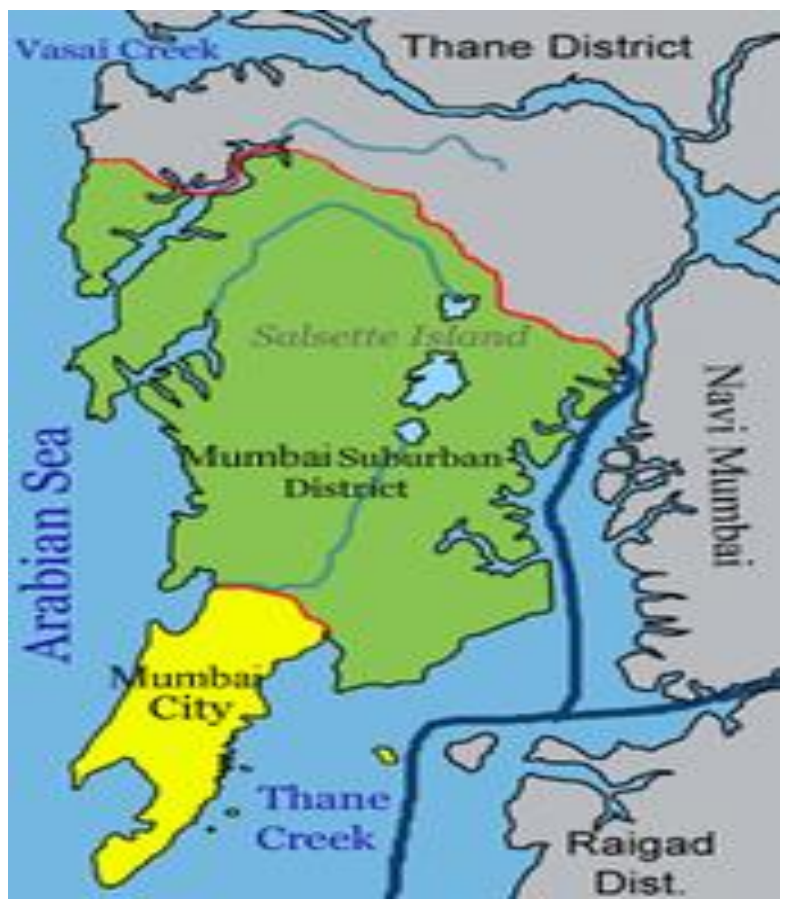

Figure 1. Study area (map not to scale)

\section{METHODOLOGY}

The overall methodology involves procurement of satellite data and landcover classification using MLE.

\subsection{SATELLITE DATA}

Cloud free and georeferenced IRS P6 LISS III images (23m x 23m, Path: 94; Row: 59) of January 20, 2004 and February 25, 2013 of Mumbai city and adjoining areas were procured from NRSC, Hyderabad. Analyses were performed using two softwares namely, GRAM++ version 11.1 and ERDAS IMAGINE version 9.3.

\subsection{LANDCOVER CLASSIFICATION USING MAXIMUM LIKELIHOOD ESTIMATOR}

Supervised classification with MLE was used to facilitate landcover classification. Classification utilizing the 
green, red and near IR bands of IRS P6 LISS III satellite were considered, namely Band 2, Band 3 and Band 4 and Standard False Colour Composite (FCC) was generated [25]. We first identified three landcovers in the study area namely, Dense mangroves, Sparse mangroves and Others based on visual photo interpretation techniques. The samples for each of the three landcovers were extracted. Using the sample statistics information of these landcovers and MLE, we classified the each pixel of the image in either of these landcover classes and generated landcover map of the study area. This analysis was performed for both the images of IRS P6 LISS III i.e. January 20, 2004 and February 25, 2013 in ERDAS Imagine. Further analysis was performed in GRAM++. Using the classified images, different layers were created and digitized in GRAM++ namely sparse, dense and others. An additional layer of Mumbai boundary was also made within which the digitization was done. While digitizing, assumptions were made like mangroves exist along the coastlines. After digitizing, various polygons were cleaned, labeled, and topology was generated. Next step was the process of rasterization. The rasterized map of 2004 and 2013 are presented in Figure 2 and Figure 3 respectively. Further, change detection with unconditional overlay was performed between 2004 and 2013 images using Raster Analysis tool. The temporal changes in landcover classes from 2004 to 2013 are depicted in Figure 4.

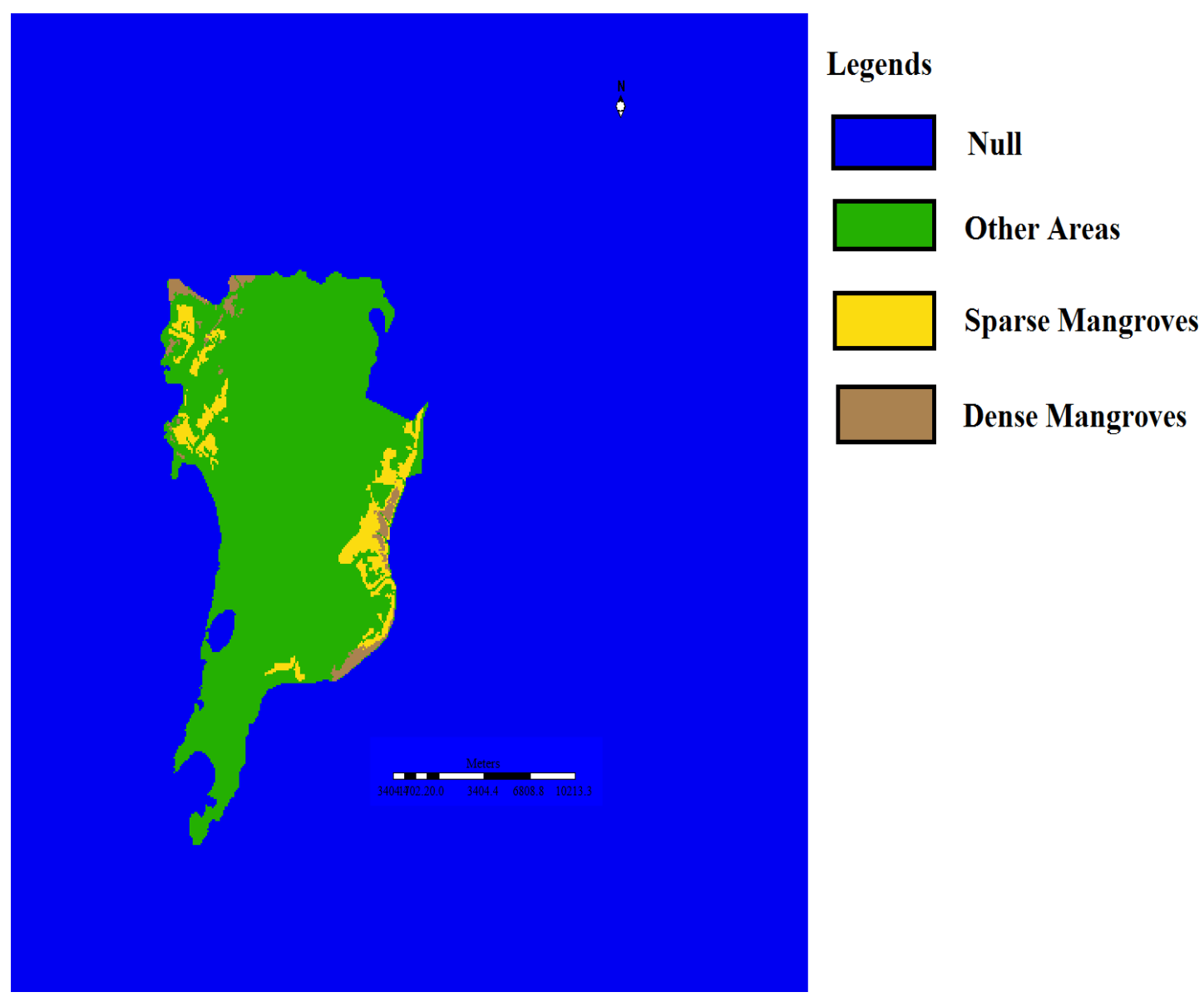

Figure 2. Mangrove mapping for year 2004 


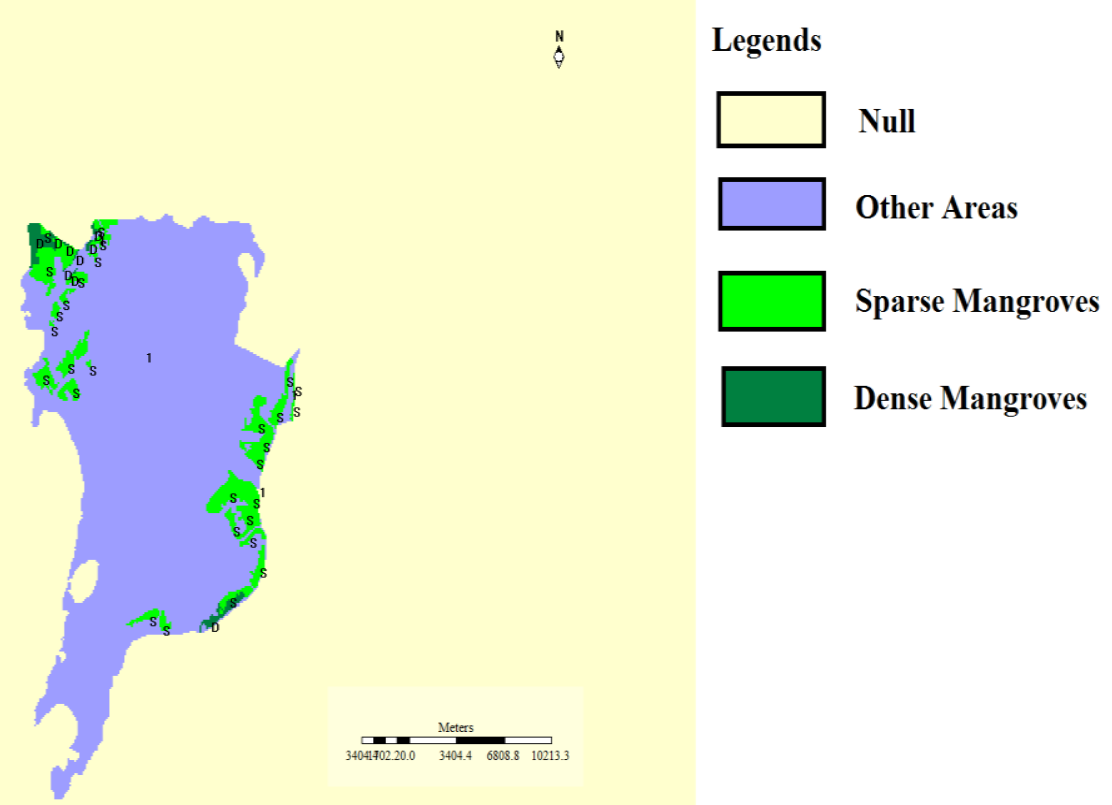

Figure 3. Mangrove mapping for year 2013

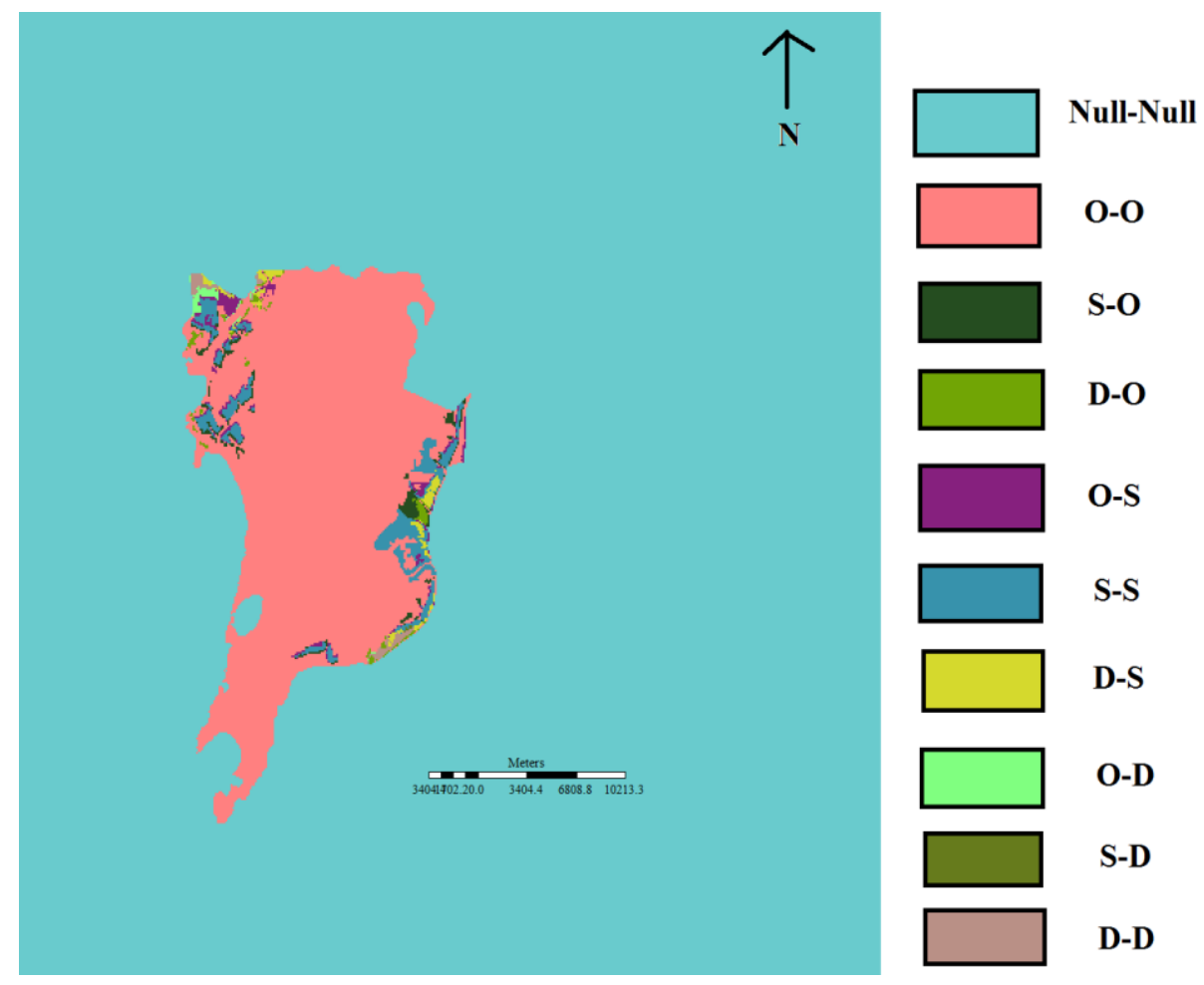

Figure 4. Change detection map for mangroves

\section{RESULTS AND DISCUSSION}

The study revealed that mangrove area in Mumbai during 2004 was 50.52 square kilometers whereas in year 2013, mangrove area was 48.7 square kilometers (Table 1). Forest Survey of India (FSI) reported 50 square kilometers of mangrove area in the study area during year 2015 [26]. The total mangrove area in the study area in year 2001 was reported as 56.4 square kilometers [27]. The results observed a decreasing trend that collaborates with past literatures. In case of Mumbai, the decreasing trend is mainly attributed to land reclamation and urban development encroached on mangroves. 
Table 1. Area of Mangroves in Mumbai

\begin{tabular}{cccc}
\hline \multirow{2}{*}{ Year } & \multicolumn{2}{c}{$\begin{array}{c}\text { Mangrove Classes } \\
\text { Dense }\left(\mathbf{k m}^{\mathbf{2}}\right)\end{array}$} & $\begin{array}{c}\text { Total Area } \\
(\mathbf{k m})\end{array}$ \\
\hline 2004 & $36.53(72.31 \%)$ & $13.99(27.69 \%)$ & $50.52(100 \%)$ \\
2013 & $42.4(87.06 \%)$ & $6.30(12.94 \%)$ & $48.70(100 \%)$ \\
\hline
\end{tabular}

In the years 2004 and 2013, contribution of sparse mangrove in the study area was $72.31 \%$ and $87.06 \%$ respectively. The coverage of dense mangrove and sparse mangrove for years 2004 and 2013 are tabulated in Table 1. It was estimated that 1.82 square kilometers of mangrove area was lost over the course of 2004 to 2013. There was a loss of 7.69 square kilometers of dense mangrove but sparse mangrove increased by 5.87 square kilometers during the period. Change detection analysis depicted dense mangroves to sparse mangroves and others were 5.68 and 4.47 square kilometers respectively. Further, conversion of sparse to dense and others were 0.155 and 8.95 square kilometers respectively. Conversion of others to sparse mangroves was 9.29 square kilometers and others to dense mangroves area was 2.31 square kilometers (Table 2).

Table 2. Change Detection of Mangroves in Mumbai from 2004 to 2013

\begin{tabular}{cc}
\hline Change Detection Parameters & Mangrove Area $\left.\mathbf{( k m}^{\mathbf{2}}\right)$ \\
\hline Sparse to Others (S-O) & 8.95 \\
Dense to Others (D-O) & 4.47 \\
Others to Sparse (O-S) & 9.29 \\
Sparse to Sparse (S-S) & 27.42 \\
Dense to Sparse (D-S) & 5.68 \\
Others to Dense (O-D) & 2.31 \\
Sparse to Dense (S-D) & 0.155 \\
Dense to Dense (D-D) & 3.84 \\
\hline
\end{tabular}

\section{CONCLUSION, LIMITATION AND FUTURE WORK}

The study attempted to monitor changes in mangroves during past decade in an industrialized urban environment. The supervised classifications with MLE results reported in the present study were comparable with literature results. In the present study, we classified mangroves with sparse and dense based on tone/color. The method was simple, rapid and easy to use. The study did not report accuracy of landcover classification as survey was not available that associated with the time of image taken. Also, spatial resolution played important role in any landcover classification. The present study used medium resolution satellite images. For classification of mangrove into various species, high resolution satellite images are needed. Future work includes classification of mangrove and its species using high resolution satellite images for better management.

For effective eco-rehabilitation and management of mangrove areas in Mumbai, there is a need of more and better information on the structure. As mangrove ecosystems have its own structure and composition, detailed sub area studies are desirable, so as to draw guidelines for the management of respective mangrove ecosystems. In addition to generating and making available alternative fuel, fodder and timber, simultaneous measures to protect the remaining mangroves, as also increasing the same, are necessary. Intensive studies, not only of plant cover but also of other components of the ecosystem should be undertaken using remote sensing and survey methods. More importantly, protection to this ecosystem is a desirable and must.

\section{Conflict of Interests}

The authors declare that there is no conflict of interests regarding the publication of this paper.

\section{Acknowledgement}

The researchers express sincere thanks to Dr. Mangesh G. Korgaonker, Director General, NICMAR for funding the Remote Sensing data and developing infrastructure at our institute for carrying out this research. Also, his 
research and technical inputs, constant support and encouragement were helpful in the successful completion of the project.

\section{References}

[1] Robertson, A. I. and Phillips, M. J (1995). Mangroves as Filters of Shrimp Pond Effluent: Predictions and Biogeochemical Research Needs, Hydrobiologia, 295, 311-321.

[2] Mazda, Y., Magi, M, Kogo, M. and Hong, P. N. (1997). Mangroves as a Coastal Protection from Waves in the Tong King Delta, Vietnam, Mangroves and Salt Marshes, 1, 127-135.

[3] Dixon, J. A. (1989). The Value of Mangrove Ecosystems, Tropical Coastal Area Management Newsletter, 4, 5-8.

[4] Lucy, E. (2006). Counting Mangrove Ecosystems as Economic Components of Asia's Coastal Infrastructure. Proceedings of International Conference and Exhibition on Mangroves of Indian and Western Pacific Oceans (ICEMAN 2006), August 21-24, Kuala Lumpur, 1-14.

[5] Giri, C., Ochieng, E., Tieszen, L. L., Zhu, Z., Singh, A., Loveland, T., Masek, J. and Duke, N. (2011). Status and Distribution of Mangrove Forests of the World using Earth Observation Satellite Data, Global Ecology and Biogeography, 20(1), 154-159.

[6] Nayak, S., Chauhan, P., Chauhan, H. B., Bahuguna, A. and Nath, A. N. (1996). IRS 1C Applications for Coastal Zone Management, Current Science, 70(7), 614-618.

[7] Blasco, F., Aizpuru, M., Gers, C. (2001). Depletion of the Mangroves of Continental Asia, Wetland Ecology and Management, 9, 255-266.

[8] Gao, J. (1999). A Comparative Study on Spatial and Spectral Resolutions of Satellite Data in Mapping Mangrove Forests, International Journal of Remote Sensing, 20(14), 2823-2833.

[9] Nakhawa, A. D., Vichare, P. S., Markad, S., Khandagale, P. A., Shirdhankar, M. and Brahmane, M. J. (2017). Mangrove Mapping of Different Estuaries Along Ratnagiri Block using Remote Sensing, 23(2), 870-875.

[10] Rudiastuti, A. W., Yuwono, D. M. and Hartini, S. (2018). Mangrove Mapping using SPOT 6 at East Lombak Indonesia, Earth and Environmental Science, 165, 1-14.

[11] Nandy, S. and Kushwaha S. P. S. (2011). Study on the Utility of IRS 1D LISS-III Data and the Classification Techniques for Mapping of Sunderban Mangroves, Journal of Coastal Conservation, 15(1), 123-137.

[12] Reddy C. S., Pattanaik, C., Murthy, M. S. R., (2007). Assessment and Monitoring of Mangroves of Bhitarkanika Wildlife Sanctuary, Orissa, India using Remote Sensing and GIS, Current Science, 92(10), 1409-1415.

[13] Dwivedi, R. S., Rao, B. R. M., Bhattacharya S (1999). Mapping Wetlands of the Sundarban Delta and its Environs Using ERS-1 SAR Data. International Journal of Remote Sensing, 20(11), 2235-2247.

[14] Hu, L., Xu, N., Liang, J., Li, Z., Chen, L. and Zhao, F. (2020). Advancing the Mapping of Mangrove Forests at National-Scale using Sentinel-1 and Sentinel-2 Time-Series data with Google Earth Engine: A Case Study of China, Remote Sensing, 12, 1-22.

[15] Nayak, S., Bahuguna, A., Shaikh, M. G. and Rao, R. S. (1991). Manual for Mapping of Coastal Wetlands/Landforms and Shoreline Changes using Satellite Data, Technical Note, IRS-UP/SAC/MCE/TN/32/91 (Space Applications Center, Ahmedabad), 63.

[16] Nayak, S. and Bahuguna, A. (2001). Application of Remote Sensing Data to Monitor Mangroves and Other Coastal Vegetations of India, Indian Journal of Marine Sciences, 30(4), 195-213

[17] Pattanaik, C. and Prasad, S. N. (2011). Assessment of Aquaculture Impact on Mangroves of Mahanadi Delta (Orissa), East Coast of India Using Remote Sensing and GIS, Ocean and Coastal Management, 54(11), 789-795.

[18] Desai, P. S., Narain, A., Nayak, S. R., Manikiam, B., Adiga, S. and Nath A. N. (1991). IRS-1A Applications for Coastal and Marine Resources, Current Science, 61(3 and 4), 204-208.

[19] Blasco, F. and Aizpuru, M. (2002). Mangroves along the Coastal Stretch of the Bay of Bengal: Present Status, Indian Journal of Marine Sciences, 31(1), 9-20.

[20] Chen , N. (2020). Mapping Mangrove in Dongzhaigang, China using Sentinel-2 Imagery (2020), Journal of Applied Remote Sensing, 14(1), 014508.

[21] Roy, S., Mahapatra, M. and Chakraborty, A. (2019). Mapping and Monitoring of Mangrove along Odisha Coast based on Remote Sensing and GIS Techniques, Modeling Earth Systems and Environment, 5, 217-226.

[22] Perea-Ardila, M.A., Oviedo-Barrero, F., Leal-Villamil, J. (2019). Mangrove Forest Mapping Through Remote Sensing Imagery: Study Case for Buenaventura, Colombia. Revista de Teledetección, 53, 73-86.

[23] Zhang, X., Treitz, P. M., Chen, D., Quan, C., Shi, L. and Li, X. (2017). Mapping Mangrove Forests using Multitidal Remotely-Sensed Data and a Decision-Tree Based Procedure, Int J Appl Earth Obs Geoinformation, 62, 201214.

[24] Liu, X, Fatoyinbo, T. E., Thomas, N. M., Guan, W. W., Zhan, Y., Mondal, P., Lagomasino, D., Simard, M., Trettin, C. C., Deo, R. and Barenblitt, A. (2021). Large-Scale High-Resolution Coastal mangrove Forests Mapping Across West Africa With Machine Learning Ensemble and Satellite Big Data, Frontiers in Earth Science, 8:560933.

[25] Lillesand, T. M. and Kiefer, R. W. (1994). Remote Sensing and Image Interpretation, 3rd Edition, John Wiley and Sons.

[26] http://fsi.nic.in/isfr-2015/isfr-2015-mangrove-cover.pdf (last accessed on March 26, 2020)

[27] Vijay, V., Biradar, R. S., Inamdar, A. B., Deshmukhe, G., Baji, S. and Pikle, M. (2005). Mangrove Mapping and Change Detection around Mumbai, Indian Journal of Marine Sciences, 34(3), 310-315. 